\title{
Teacher Knowledge and Skill for Gifted and Talented Education
}

\author{
Songzhu Mei ${ }^{1}$, Ping Leng ${ }^{2 *}$, Ximeng Dai ${ }^{1}$, Zifang $\mathrm{Li}^{1}$, Zhimin $\mathrm{Ma}^{\mathbf{1}}$ \\ ${ }^{1}$ Educational College, Huaibei Normal University,Huaibei Anhui, China \\ ${ }^{2}$ College of Mathematic and Science, Huaibei Normal University, Huaibei Anhui, China
}

*Corresponding Author.

\begin{abstract}
The gifted and talented education is one of national strategic projects, and the teachers of gifted and talented education are the core elements of gifted and talented education, which determine the quality of gifted and talented education. Exploring and analyzing professional development, the knowledge and skills in the new period from such ten aspects as theoretical basis, teaching characteristics, individual differences, learning strategy, learning environment,language and communication, teaching plan, talent evaluation, professional ethics, multi-dimensionalcooperation, we can draw an enlightenment that the developing quality of teachers of gifted and talented education can be raised by legislation, policy, planning, resources, guarantee, project and localization, which also provide solid support of manpower and intelligence for gifted and talented education.
\end{abstract}

Keywords: Teacher of gifted and talented education, knowledge and skill, standards, enlightenment

With the development of economic globalization, the competition of human resources is becoming increasingly fierce. As a strategic scarce resource of the country, talents have attracted much attention. More and more countries begin to pay attention to the education of talents, and teachers, as the educators of talents, are more rare human and intellectual resources, which play a decisive role in the implementation of talents education.

\section{Question Raising}

1.1 Do gifted education teachers need specific knowledge and skills

About whether talents education teachers require specific knowledge and skills, has been controversial. Due to the influence of traditional ideas and the lack of understanding of professionalization of talented education teachers, some people think that a member of the elite teachers than ordinary teachers, there is no essential difference with other teachers, so there is no so-called specific knowledge and skills. On the contrary, some people think that the elite is a special group, they need a certain degree of difficulty and complexity of learning content, need a certain amount of innovation-oriented judgment teaching guidance, need an objective multidimensional comprehensive achievement evaluation, therefore destined to provide the needed elite education teachers are not ordinary teachers, they should be more specialized in the areas of knowledge and skills.

Based on the actual evidence of elite education around the world, all countries with good development of elite education provide specialized professional development training for teachers of elite education, and have detailed and unified standards in terms of knowledge and skills. The National Association for Gifted Children, which sets national standards for the knowledge and skills of gifted teachers.Required talents education teachers can know coming from under the background of cultural diversity and diversification of the differences of study of person of outstanding ability, talent development milestone, cognitive and emotional characteristics, can design the proper teaching contents and teaching plan to improve the creativity of talents, to choose, adjust and adapt to the right, based on the evidence of teaching strategies to develop elite talent. These knowledge and skills are not possessed by ordinary teachers, which reflects the highly professional and irreplaceable nature of elite education teachers, and also reflects the systematic and continuous training of elite education teachers.

1.2 The meaning of gifted teachers' knowledge and skills

ISSN: 0010-8189

(C) CONVERTER 2021

www.converter-magazine.info 
In 1986, Lee Shulman put forward "Pedagogical Content Knowledge" in view of the "lack of paradigm" in the American teacher certification system. After that, many scholars combined PCK with other specific knowledge and skills and proposed knowledge frameworks for teacher professional development, such as T-PACK and MPCK. As a special group of educators, gifted teachers have "Gifted Knowledge" (GK), "Pedagogical Knowledge" (PK), "Content Knowledge" (PK) and "Gifted Knowledge" (GK). CK and Technological Knowledge (TK) are the most core elements in the process of professional development and the implementation of elite education, which can be defined as GPCTK model,The Venn diagram of the structure is as follows:

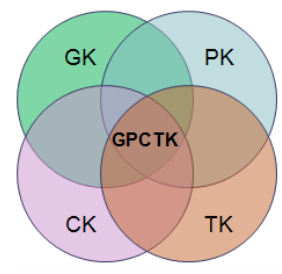

Fig 1: Venn diagram of GPCTK model

GPCTK is the unique and most precious knowledge for talented teachers. It is not the simple superposition of four kinds of knowledge, but the integration and connection of each other to form a knowledge complex, which reflects the comprehensive, efficient and three-dimensional utility. With the growth of teaching skills and educational experience of elite education teachers, GPCTK will continue to expand and integrate, and become the core driving force and foundation of their professional development. In order to promote the growth of GPCTK, elite education teachers need to strengthen a variety of knowledge and skills to gain professional understanding and experience of theories and practices related to elite education, so as to improve their professional development potential and promote the in-depth development of elite education.

\section{Teachers' Knowledge and Skills for the Gifted Education}

\subsection{Basis}

Gifted \& talented child/student, which has no universal definition, usually refers to people with "giftedness" and talent in one or more domains (mathematics, music, languages, painting, dance, sports). Their performance was in the top $10 \%$ of their group. Spearman believes that talent is general intelligence, while Cattell's fluid and crystal intelligence theory and Gardner's multiple intelligences theory believe that talent is related to specific fields such as academic output, leadership, creativity and art. Contemporary scholars generally believe that talent is a dynamic concept, whose development is influenced by both heredity and environment, and talent can be identified by measurement and evaluation methods.

Gifted-talented education (GIFT) is a special education program for gifted talents, which aims to develop their potential, achieve developmental equity, cultivate elite and strategic talents, and enhance their international competitiveness. In 1988, the US enacted the Jacob K. Javits Gifted and Talented Students Act. In 1990, the National Talent Research Center (NRC/GT) was established. In 2006, the National Education Standards for Talents was issued. So far, gifted education has been recognized and accepted by most countries, but there are still some disputes about its necessity, fairness and legitimacy.

The theoretical basis of elite education is very broad, including brain science, humanism, educational economy, cognitive psychology, and so on. A country's ideology, values, language habits, cultural structure, economic development level and talent training framework all affect the process and effect of elite education. The education of talents not only reflects the strategic decision and far-sighted view of the country, but also shows the interactive effect of social and cultural thoughts and educational development ideas. Gifted education requires the removal of certain prejudices: that intelligence is inherited, that equality precedes excellence, that meritocracy is encouraged by meritocratic programmes, that all children are talents.

ISSN: 0010-8189

C CONVERTER 2021

www.converter-magazine.info 
Talent development depends on talent and genes on the one hand, and guidance and nurturing on the other. Without the guarantee of gifted education, even those who are identified as meritocracy can hardly give full play to their talents. Poverty, minority background, cultural barriers, anti-intellectualism, physical disability, low self-efficacy, emotional crisis of motivation, gender, ethnic discrimination, lack of nourishing environment and conditions are the main factors that affect the development of talents.

Identifying talent requires the use of testing and evaluation, both standardized and domain specific. Test of Mathematical Abilities for Gifted Students, Screening Assessment for Gifted Students, Stanford Binet Scale, Wescher Intelligence Scale, Cognitive Abilities Test, Naglieri Nonverbal Ability Test and CogAT,Otis-Lennon,Hemmon-Nelson,Ravens Progressive Matrices,Matrix Analogies Test, provide objective and systematic evidence for the identification and selection of meritocracy.

\subsection{Development and characteristics of learners}

The elite is a special group. Common characteristics include: Abnormal alert, open-ended questions, the interest is extensive, curious, a good memory, vocabulary, high learning efficiency, long focused, like Numbers and puzzles, good at reading and writing, have a strong sense of humor, highly sensitive, emotional, and, the abstract, logical thinking, good at insight and imaginative people or things, do things alone, like planning, idealism and finish Americanist. Interested in social and political issues and issues of injustice. Of course, not all talents have these characteristics at the same time. An outstanding person may excel in some areas, while performing mediocre or lagging behind his peers in others. Talent often manifests itself early in development, and extensive reading of books, use of sign systems, and understanding of abstractions are all biological underlies of early intervention for excellence. If the right educational environment and support are provided, the elite will generally achieve high achievement expectations.

\subsection{The learning difference of the elite}

Outstanding individuals have great differences in cognition, emotion, ability, needs and other aspects. Compared with their peers, the elite perform better in psychological adjustment and achievement motivation, but show no obvious advantages in social and emotional issues (consciousness, anxiety, pressure, peer relationship). Even some elite of small groups actively resist success for fear of being caught in the so-called mainstream culture. There are many factors that can cause the individual differences of person of outstanding ability, internal factors are genetic, external factors including nationality, race, language, religion, sexual orientation, social culture, family background, the geographical position, whether disability, socioeconomic status, etc..These factors will further influence the attitude of the person of outstanding ability, interest, values, learning needs and learning style, academic output and social behavior.

Culture has the most extensive influence on the development of talents, such as the formation of identity, responsibility, self-concept, achievement motivation. Academic internal motivation is one of the characteristics of talent, which is meaningful, positive, unique, and influenced by the environment. If the culture and environment do not match the learning needs and abilities of the talented, it will inhibit the development of talent. Underachievers can be enhanced by providing them with the right level of challenge, or by using cultural or psychological interventions.

\subsection{Teaching strategy}

Talent education teachers in addition to possess general teachers' teaching strategies, you can also use meta-cognitive strategy, high level of the thinking strategies to stimulate learning interest and achievement motivation, according to the special learning needs to select the course of person of outstanding ability, teaching and management strategy, to provide the exploration, development and research of self-interest and talent, The three forms should also adopt

ISSN: 0010-8189

C CONVERTER 2021

www.converter-magazine.info 
culturally responsive teaching strategies, that is, treat the diversity of talents and conduct effective teaching based on cultural characteristics, experience and perspectives. Teachers of elite education need to consider the cognitive process of elite children from the perspective of the complex system of cognitive development psychology, keep sensitive to their emotional needs, provide challenging cross-cultural courses for them, and use information technology to assist their cognitive development.

There are many models of gifted teaching, including acceleration, enrichment, grouping, layered, as well as Autonomous Learning, Integrated Curriculum, Parallel Curriculum, Kaplan Grid, and Purdue Three Stage, Talents Unlimited, which all emphasize the role of learning interest, learning environment and growth catalyst.

\subsection{Learning environment and social role}

Environment (family, school, community, society) is crucial to the development of a talented person. A positive environment can enhance talents' self-awareness, self-efficacy, leadership and lifelong learning. Safe environment can encourage talents to participate in various activities, improve their sense of cooperation and sharing and positive peer relationship; A cross-cultural environment can guide talents to respect and appreciate their own and others' language and cultural heritage, and to develop social interaction and coping skills to address personal or social problems such as discrimination and stereotyping.

School cultivation, family support, cross-cultural appreciation, sensitivity and motivation contribute to the success of talents, while the factors that hinder their success may be due to the mismatch between curriculum activities and learning style, inappropriate classroom placement and unstable family structure. Among all kinds of environments, family environment is the most critical and fundamental for the growth of talents, which is reflected in their values, trust relationship, pressure release, self-adaptation, and interaction with other systems (school, neighbors, peers).

Some people believe that because the elite are better at adapting and adjusting, they don't need special guidance or help, either academically or emotionally. In fact, this is a kind of misplaced prejudice, is others for the talent of the false guess. The intellectual, cognitive and emotional development of the elite is not necessarily balanced. We often see that the emotional development of the elite lags behind the intellectual development seriously, resulting in the obstacles in interpersonal relationship and self-knowledge of the elite. Many performers believe that the highest level of learning is self-developing learning with the support, trust, respect, and guidance of an educator, parent, or mentor. They also need to learn from the successful people around them and see them as mentors, role models, or heroes. Proper psychological counseling is also necessary because talented people often don't feel complacent about their talents that are appreciated by others. Instead, they feel a little depressed when their talents are not being used. In addition, the will of talents should also be respected, and their emotional well-being should not be neglected due to the psychological pressure caused by excessive expectations of achievement. Elites are individuals with rights to understand their talents and strengths, to make mistakes, to seek guidance, to have diverse peers, and to choose areas of talent that interest them.

\subsection{Language and communication}

Communication is an effective way of learning. It is also a good way of emotional communication. It is especially important for talents. The communication will take the form of oral and written discussions, speeches, lectures, reports, online forums, online Q\&A, etc. Diversity of communication can improve the efficiency of interaction of person of outstanding ability, increase output, education also can stimulate the talents more efficient use of available resources or develop strategies to improve the learning efficiency and learning experience, or in the process of interaction to form stable leadership, enhance the inference, plan of person of outstanding ability, thinking skills, problems found and solved, as well as the concept, feature, the idea of learning.

In the process of talent identification, selection and training, some old prejudices and discrimination will be aggravated by cultural barriers, language barriers and poor communication, resulting in some Niche talents are

ISSN: 0010-8189

C CONVERTER 2021

www.converter-magazine.info 
neglected or ignored. In fact, people who are socially and culturally disadvantaged can develop their own feelings, thoughts, and empathy by understanding the real experiences of others. In order to make up for the lack of small language background, I can try to use mainstream language vocabulary, language comparative analysis, practice native pronunciation, interpretive translation, and obtain courses in cross-cultural background and interdisciplinary.

Culture, language and communication can promote or restrict the development of talents, and there are differences between different genders. Image management, self-pressure, alien labels, male-dominated needs, cultural expectations, and gender role conflict are issues that male talents often face. Women of excellence often do not recognize their existence and contributions as women, so they can choose to improve this situation by portraying strong women, using historical texts that include important women's issues and roles, and discussing social issues and reforms that transcend gender.

\subsection{The teaching plan}

The teaching plan of elite education teachers is a differentiated course designed based on the personalized needs of elite, which needs to pay attention to the particularity and difference of the cognitive, emotional, motor, social and linguistic fields of elite, and provide advanced, conceptually challenging, profound, differentiated and complex content. A differentiated curriculum can be designed using process, content, output relationships, or layering techniques.

The teachers of elite education also need to integrate the career guidance of elite talents into the teaching planning and select and adjust the appropriate teaching mode to stimulate the learning needs and achievement expectations of elite talents. The course mode of elite teaching mainly includes the acceleration mode of shortening the study period and intervening advanced courses in advance, the enrichment mode of expanding, deepening the synchronous course, the problem-based learning mode, and the mode of curriculum compacting and extracurricular activities. In addition, there are some elite who advocate independent learning mode, which includes five dimensions: orientation, personal development, enrichment activities, seminars, and in-depth research. The elite can freely choose the learning path that they are interested in or good at, and give full play to the self-guiding role of learning. Teachers of elite can also use individualized instructional guidance programs, including grouping according to instructional needs, reducing class sizes, providing special resources, increasing instructional time, and utilizing instructional support staff.

\subsection{Evaluation}

Evaluation is not only one of the procedures of elite education, but also an indispensable factor to guarantee the quality of elite education. It needs to be used in every link of elite education. Formal or informal evaluations can be used to separate the top performers from their group, Including Dynamic Evaluation, Peer Nomination, Observations, Nonverbal Tests, and Real Tasks, Portfolio, Screenings, Alternative, and Performance evaluation can be used to combine qualitative and quantitative evaluation, as well as cross-cultural curriculum and problem solving based evaluation. In general, the evaluation of talents requires three aspects: the academic performance in a specific field, the creative productivity in a specific field or across disciplines, and the long-term creative productivity. The use of core evaluation criteria to evaluate specific talent areas, the selection of appropriate data resources and evaluation tools, the collection, organization and interpretation of evaluation data, the writing of evaluation reports, and planning, analysis, guidance, archiving, performance evaluation and authenticity evaluation are all important ways to evaluate talent.

Any evaluation technique has both advantages and limitations. The principle of evaluation selection is to provide appropriate learning guidance for talents, to enable them to obtain appropriate courses and resources, as well as the appropriate level, depth and progress of learning experience. At the same time, it is necessary to use non-biased and fair methods to identify talents, use technical adequate evaluation to place talents, develop differentiated curriculum-based evaluation to carry out teaching planning, or use alternative evaluation techniques to make up for

ISSN: 0010-8189

C CONVERTER 2021

www.converter-magazine.info 
some unavoidable defects of evaluation.

\subsection{Professional and ethical practice}

Effective teaching relies on high educational output objectives, core quality standards, teaching skills and behavior, and continuous professional development. The teacher's personal educational experience and cultural framework of elite education will influence the process and effect of elite teaching. In view of the elite culture, race and language differences, talent education teachers need to have certain cultural education theory, cultural sensitivity evaluation, education fairness, education philosophy, the public idea of professional, have the empathy of understand the needs of the students at the same time, able to create a safe learning environment, expectations of students have the right, good at using encouragement, praise, humor and other ways.

Talent education teachers need to be performed and talent education of law, policy and ethics of elite education, in view of objective and fair evaluation the lack of professional knowledge and skills in the development of self, through constant based on the study of professional development to improve the education practice, actively join the elite education professional organizations and participate in all kinds of talent education professional training, using talents education and teaching resources and professional growth materials to promote my professional development.

\subsection{Cooperation}

Talent education is a systematic process, which requires effective communication and cooperation from various parties. Teachers of elite work with elites, elite families, educators in general, special educators, community members, evaluators, and other stakeholders, and consult with school staff about the characteristics and needs of elite. Teachers of elite education should have a cross-cultural awareness and a vision of fairness. They should be aware that their prejudices, assumptions and stubbornness may affect the selection and cultivation of elite talents, understand the difference and fairness of elite education from different cultural perspectives, and provide timely opportunities for elite education to minority elites. Elites teachers need to focus on helping elites parents understand elites' characteristics and learning needs, elites' educational resources, elites' controversies, school options, elites' organizations and groups.

\section{Revelation}

China's elite education started late and developed slowly. So far, there is no national standard for elite education, let alone the knowledge and skills standards for elite education teachers. Based on the theoretical and practical achievements of elite education in the international scope, and combined with the deficiencies in the professional development of teachers of elite education in China, the following points are worthy of reflection and reference: Firstly, we should strengthen the legislation and publicity of the education of talents, raise the awareness of the whole people, avoid misunderstanding and subjective prejudice, create a benign environment for the education of talents, and raise the cultivation of talents and the development of teachers of the education of talents to the height of national strategy; Secondly, we should establish national standards for elite education teachers, unify the admission requirements of elite education teachers, standardize their selection and training procedures, and combine the qualification recognition of elite education teachers with the policy system of elite education; Thirdly, it is to develop talent education teacher professional development planning, establishment of talent management and development of school education teachers, the training mode of diversification, according to certain steps and evidence based on the evaluation of implementation of talent education teachers' pre-service education and post-career training, improve the talent education teachers' knowledge and skills, expand its GPCTK, form a solid foundation and power professional development; Fourthly, enrich the training courses and resources of elite education teachers, strengthen the cooperation among the stakeholders of elite education, and improve the training benefits of elite education teachers; Fifthly, to improve the professional development guarantee system of elite education teachers, to provide professional guidance, financial support and training sites for the professional development of elite education teachers; Sixthly, promote the implementation of talents education projects,

ISSN: 0010-8189

C CONVERTER 2021

www.converter-magazine.info 
strengthen exchanges and cooperation between talents education institutions, and provide practical opportunities for the professional development of talents teachers; Seventhly, we should learn from the advanced measures of the developed countries to establish the research institutions of the teachers of the elite education and carry out the localization reform based on the current situation of the development of the teachers of the elite education in China.

In short, talent education teachers' professional development is a long-term, ambitious, strategic project. We must abandon the old prejudices, but to give up of your thoughts, realize the importance of the education of person of outstanding ability and the crisis in our country, for improving the quality of talent education in our country, improve the international competitiveness, to cultivate a professional level higher and research talents education teachers.

\section{Acknowledgements}

This research was supported by Anhui Provincial Philosophy and Social Science Planning Project "Research on Collaborative Promotion of Rural Revitalization in the New Era and Tailed-in Education Poverty Allowance Strategy" (Grant No. AHSKY2019D058); the result of "Investigation and Research on the Academic Burden of Primary and Secondary Schools in the Perspective of Reducing Burden" (Grant No. SK2020A0062), a key project of Humanities and Social Sciences in Universities of Anhui Province.

\section{References}

[1] L.S. Shulman. "Knowledge and Teaching: Foundations of the New Reform,"Harvard Educational Review,vol.57,no.1,pp.1-22,1987.

[2] D.Y. Ford, C.J. Russo. "Meeting the educational needs of the gifted: A legal imperative," Roeper Review, no.17,pp.224-228,1995.

[3] B.Clark."Social ideologies and gifted education in today's schools," Peabody Journal of Education, vol.72,no.34,pp. 81-100,1997.

[4] E.I.Diaz."Perceived factors influencing the academic underachievement of talented students of Puerto Rican descent,"Gifted Child Quarterly, no.42,pp.105-122,1998.

[5] L.M. Henderson,F.F. Ebner, “The biological basis for early intervention with gifted children,"Peabody Journal of Education, vol.72,no.34,pp.59-80,1997.

[6] M. Neihart."The impact of giftedness on psychological well-being: What does the empirical literature say?’Roeper Review, no.22,pp.10-17,1999.

[7] J.U. Ogbu. "Understanding cultural diversity and learning,"Journal for the Education of the Gifted, no.17,pp.355-383,1994.

[8] M.S. Matthews, E. Shaunessy. “Culturally,linguistically, and economically diverse gifted students. In F.A.Karnes \& K.R.Stephens (Eds.), Achieving excellence: Educating the gifted and talented,” Upper Saddle River, NJ: Pearson, pp.99-115,2008.

[9] D.Y. Ford, J.L. Moore III, H.R.Milner."Beyond culture blindness: A model of culture with implications for gifted education,'Roeper Review, no.27,pp.97-103,2005.

[10] A.E. Gottfried, A.W.Gottfried."Toward the development of a conceptualization of gifted motivation," Gifted Child Quarterly, no.48,pp.121-132,2004.

[11] S.M. Baum, J.S. Renzulli, T.P. Hebert,"Reversing underachievement: Creative productivity as a systematic intervention,”Gifted Child Quarterly, no.39,pp.224-235,1995.

[12] S.M. Moon, J.F. Feldhusen, D.R. Dillon. "Long-term effect of an enrichment program based on the Purdue three stage model,”Gifted Child Quarterly,no.38,pp.38-48,1994.

[13] G.Gay. "Preparing for culturally responsive teaching,"Journal of Teacher Education, no.53,pp.106-116,2002.

[14] H.H.Steiner, M. Carr."Cognitive development in gifted children: Toward a more precise understanding of emerging differences in intelligence,"Educational Psychology Review, no.15,pp.215-246,2003.

[15] S.Mendaglio."Sensitivity among gifted persons: A multifaceted perspective,"Roeper Review, no.17,pp.69-72,1995.

[16] F.Gagné"Transforming gifts into talents: The DMGT as a developmental theory. In N. Colangelo \& G.Davis (Eds.), Handbook of gifted education (3rd ed.),"New York: Pearson, pp.60-74,2003.

ISSN: 0010-8189

(C) CONVERTER 2021

www.converter-magazine.info 
[17] T.P. Hébert.“Gifted Black males in an urban high school: Factors that influence achievement and underachievement,"Journal for the Education of the Gifted, no.21,pp.385-414,1998.

[18] S.M. Moon, J.A. Jurich, J.F.Feldhusen."Families of gifted children: Cradles of development. In R.C.Friedman \& K.Rogers (Eds.). Talent in context: Historical and social perspectives on giftedness,’Washington,DC: American Psychological Association, pp.81-99,1998.

[19] G.Betts."Fostering autonomous learners through levels of differentiation,"Roeper Review,no.26,pp.190-191,2004.

[20] M.K.Pleiss,J.F. Feldhusen."Mentors, role models and heroes in the lives of gifted children,"Educational Psychologist, no.30,pp.159-169,1995.

[21] L.K. Silverman. “The universal experience of being out-of-sync,"Advanced Development, no.8,pp.1-12,1995.

[22] B. Grant,M. Piechowski."Theories and the good: toward child-centered gifted education,"Gifted Child Quarterly, no.43,pp.4-12,1999.

[23] J.F. Feldhusen, D.M. Kennedy,"Preparing gifted youth for leadership roles in a rapidly changing society,’Roeper Review, no.10,pp.226-230,1988.

[24] M.A.Ingram. "Sociocultural poetry to assist gifted students in developing empathy for the lived experiences of others,"Journal of Secondary Gifted Education, vol.14,no.2,pp.83-90,2003.

[25] T.P.Hébert."Meeting the affective needs of bright boys through bibliotherapy,"Roeper Review, no.13,pp.207-212,1991.

[26] P.B. Kolloff, “Gifted girls and the humanities,"The Journal for Secondary Gifted Education, no.7,pp.486-492,1996.

[27] S.Kaplan."Layering differentiated curricula for the gifted and talented. In F.Karnes \& S. Bean (Eds.) Methods and materials for teaching the gifted,'Waco,TX: Prufrock Press, pp.107-132,2005.

[28] K.B.Rogers. "Effects of acceleration on gifted learners. In M.Neihart,S.M. Reis, N. M. Robinson, \& S. M. Moon (Eds.), the social and emotional development of gifted children: What do we know?'Waco, TX: Prufrock Press,pp.3-12,2002.

[29] G.T.Betts,M.Neihart."Implementing self-directed learning models for the gifted and talented,"Gifted Child Quarterly, no.30,pp.174-177,1986.

[30] M.R. Coleman.“Are we serious about meeting student needs?"Gifted Child Today, vol.21,no.1,pp.40-41,1998.

[31] V.Gonzalez."Theoretical and practical implications of assessing cognitive and language development in bilingual children with qualitative methods,"Bilingual Research Journal, no.20,pp.96-131,1996.

[32] J.H. Borland, L. Wright."Identifying young, potentially gifted, economically disadvantaged students,"Gifted Child Quarterly, no.38,pp.164-171,1994.

[33] J.S. Renzulli, M.A.B.Delcourt."The legacy and logic of research on the identification of gifted persons. In J.S.Renzulli (Ed.), Identification of students for gifted and talented programs,"Thousand Oaks, CA: Corwin Press, pp.71-78,1986.

[34] D. Treffinger."Productive thinking: Toward authentic instruction and assessment,"Journal of Secondary Gifted Education, no.6,pp.30-37,1994.

[35] J.F. Feldhusen. "Is it acceleration or simply appropriate instruction for precocious youth?"Teaching Exceptional Children, no.28,pp.48-51,1996.

[36] A. Harris."Effective teaching: a review of the literature,"School Leadership and Management, vol.18,no.2,pp.169-183,1998.

[37] D.Y. Ford, M.F. Trotman."Teachers of gifted students:Suggested multicultural characteristics and competencies,"Roeper Review, no.23,pp.235-239,2001.

[38] D. Eyre, D. Coates, M. Fitzpatrick,et al.,"Effective teaching of able pupils in the primary school: The findings of the Oxfordshire effective teachers of able pupils project,"Gifted Education International, vol.16,no.2,pp.158-169,2002.

[39] D.Y. Ford, T.C. Grantham, J.J.Harris."Multicultural gifted education: A wake up call to the profession,’Roeper Review, no.19,pp.72-79,1996.

[40] P.K. Rash.“Meeting parents' needs,"Gifted Child Today,vol.21,no.5,pp.14-17,1998. 